\title{
Effects of Neostigmine and Sugammadex for Reversal of Neuromuscular Blockade on QT Dispersion Under Propofol Anesthesia: A Randomized Controlled Trial
}

\author{
Yusuke Yamashita - Toshifumi Takasusuki • Yoshiyuki Kimura • \\ Makoto Komatsuzaki · Shigeki Yamaguchi
}

Received: July 31, 2018 / Published online: September 14, 2018

(C) The Author(s) 2018

\begin{abstract}
Introduction: Reversal of non-depolarizing neuromuscular blocking agent neostigmine is associated with QT prolongation under general anesthesia. To clarify the effects of neostigmine and sugammadex on hemodynamic status, the QT interval and QT dispersion after reversal of neuromuscular blockade were evaluated with a 12-lead electrocardiogram. To exclude QT prolongation due to sevoflurane, the present study was performed under propofol anesthesia.

Methods: After receiving approval from the ethics committee of Dokkyo Medical University Hospital, 40 patients with American Society of Anesthesiologists physical status I or II were randomly allocated to group $\mathrm{N}(n=20)$ or group $S(n=20)$. Group N was administered neostigmine $(40 \mu \mathrm{g} / \mathrm{kg})$ and atropine $(20 \mu \mathrm{g} / \mathrm{kg})$, while Group $S$ was administered sugammadex $(4 \mathrm{mg} /$ $\mathrm{kg}$ ) for reversal of neuromuscular blockade after surgery. The changes in RR interval, QT interval (QT), corrected QT interval (QTc), QT dispersion (QTD), and corrected QT dispersion (QTcD)
\end{abstract}

Enhanced Digital Features To view enhanced digital features for this article go to https://doi.org/10.6084/ m9.figshare.7042181.

Y. Yamashita · T. Takasusuki ( $₫)$. Y. Kimura .

M. Komatsuzaki · S. Yamaguchi

Department of Anesthesiology, Dokkyo Medical

University, School of Medicine, Mibu, Tochigi,

Japan

e-mail: takasusu@dokkyomed.ac.jp before and after administration of reversal agents were recorded using computerized measurements. Statistical analysis was performed using two-way analysis of variance.

Results: The RR interval significantly decreased after reversal of the neuromuscular blockade in group $\mathrm{N}$, compared with group $\mathrm{S}(p<0.05)$. Compared with group S, the QT decreased, whereas QTc and QTcD increased, in group N $(p<0.05)$. Sugammadex was not found to alter QT, QTc, QTD, or QTcD throughout the study. Conclusion: In the present study, a mixture of neostigmine and atropine, but not sugammadex, increased QTc and QTcD under propofol anesthesia. Thus, neostigmine may cause electrocardiogram abnormalities that could precede the development of fatal arrhythmias.

Keywords: Neostigmine; Propofol; QT dispersion; QT interval; Reversal of neuromuscular blockade; Sugammadex

\section{INTRODUCTION}

Several anesthesia-related drugs, such as inhaled anesthetics, and neuromuscular blockade reversal agents prolong the QT interval $[1,2]$, which is associated with torsades de pointes. Neostigmine, an anticholinesterase, has been commonly used for reversal of residual neuromuscular blockade. However, this reversal agent may increase the risk of arrhythmias, such as 
asystole or junctional rhythm [2, 3]. It may also induce bradycardia by inhibiting hydrolysis of the acetylcholine released by the parasympathetic neurons that regulate the heart [4]. Therefore, reversal of neuromuscular blockade by neostigmine has been reported to cause serious complications, such as sudden cardiac arrest, due to its cholinergic effects $[5,6]$. To avoid severe bradycardia, atropine must be given with neostigmine to reverse neuromuscular blockade. Previous studies have revealed that neostigmine prolongs the rate-corrected QT (QTc) interval on the electrocardiogram [7]. Indeed, neostigmine and glycopyrronium, a muscarinic anticholinergic agent that prevents neostigmine's muscarinic effects, caused ventricular fibrillation due to QT prolongation in a previous study [8]. Furthermore, second-degree heart block and QTc interval prolongation were observed for $4 \mathrm{~h}$ after muscle relaxant reversal using neostigmine and glycopyrronium [9]. Thus, several studies have clarified that neostigmine and glycopyrronium might cause QT interval prolongation, which is a precursor for torsades de pointes. In contrast, another report concluded that neostigmine changed the heart rate and systolic blood pressure, but not QTc [10]. Thus, the anticholinergic effects of neostigmine on the QT interval during general anesthesia remain unclear.

Sugammadex, a selective relaxant-binding agent, which is a modified $\gamma$-cyclodextrin compound, completely reverses the neuromuscular blocking effects of steroidal non-depolarizing agents by rapid encapsulation [11]. This agent affects neuromuscular blockade by preventing binding of the acetylcholine receptor in the neuromuscular junction. Unlike neostigmine, sugammadex does not block acetylcholinesterase; therefore, co-administration of atropine is not required [7]. Moreover, it has been reported that sugammadex does not prolong the QTC interval under propofol or sevoflurane anesthesia [12]. Based on these previous reports, sugammadex is believed to have fewer effects on hemodynamic status than neostigmine does.

Dispersion of the QT interval (QTD) is defined as the difference between the maximal and minimal QT interval on a 12-lead surface electrocardiogram (ECG) and reflects the regional heterogeneity of ventricular repolarization [13]. This marker has been proposed as an index of ventricular arrhythmia, which may lead to sudden cardiac death [14, 15]. Our previous study demonstrated that neither neostigmine nor sugammadex altered QT or QTD under sevoflurane anesthesia [16], but the effects of these reversal agents under propofol, an intravenous anesthetic, has not been assessed. Unlike propofol, sevoflurane is likely to increase the QT interval significantly [17].

In the current study, we sought to clarify the effects of neostigmine and sugammadex on the RR interval, QT interval, rate-corrected QT (QTc) interval, QTD, and rate-corrected QTD (QTcD), based on computerized measurements. To exclude the effects of sevoflurane on the QT interval and QTD, all measurements were conducted under propofol anesthesia.

\section{METHODS}

Forty patients with American Society of Anesthesiologists (ASA) physical status (classification of preoperative patients for anesthetic risk assessment) I or II, aged 20-65 years, who were scheduled to undergo elective otorhinolaryngological surgery, were selected, after receiving approval for the project from the ethics committee of Dokkyo Medical University and written informed consent from the patients. All procedures performed in studies involving human participants were in accordance with the ethical standards of the institutional and national research committee and the 1964 Helsinki declaration and its later amendments or comparable ethical standards. This study was registered with the University Hospital Medical Information Network (UMIN, registration number: UMIN000024742). Patients with cardiovascular, respiratory, metabolic, or cerebrovascular disease, and preoperative ECG abnormalities were excluded from this study. Patients with predicted difficulty in tracheal intubation were also excluded. No patient received antiarrhythmic drugs or drugs that posed a risk of QT prolongation, and no premedication was administered. Participants 
were randomly assigned to two groups: the patients in group $\mathrm{N}(n=20)$ received a mixture of neostigmine ( $40 \mu \mathrm{g} / \mathrm{kg}$ body weight) and atropine $(20 \mu \mathrm{g} / \mathrm{kg}$ body weight $)$ for reversal of neuromuscular blockade after the operation, while those in group $S(n=20)$ received sugammadex ( $4 \mathrm{mg} / \mathrm{kg}$ body weight).

In the operation room, standard monitoring of 12-lead ECG signals (FDX-4521L; Fukuda Denshi Co. Ltd., Tokyo, Japan), noninvasive measurement of arterial blood pressure, pulse oximetry, and assessment of bispectral index (BIS, an index for measuring the depth of anesthesia) were performed. After adequate preoxygenation, anesthesia was induced with $0.2 \mu \mathrm{g} / \mathrm{kg} / \mathrm{min}$ of remifentanil (a potent and short-acting opioid agonist) and an effect-site target propofol concentration of $3-4 \mu \mathrm{g} / \mathrm{ml}$, using a target controlled infusion (TCI) system (TE-371; Terumo Medical Corp., Shibuya, Japan). After loss of consciousness, $0.6 \mathrm{mg} / \mathrm{kg}$ of rocuronium (a non-depolarizing neuromuscular blocking agent) was administered, and manual ventilation was conducted with $100 \%$ oxygen via a facemask. Tracheal intubation was performed within $20 \mathrm{~s}$ by an experienced anesthesiologist. Anesthesia was maintained with remifentanil $(0.2-0.3 \mu \mathrm{g} / \mathrm{kg} / \mathrm{min})$, air-oxygen mixture, and $2-3 \mu \mathrm{g} / \mathrm{mL}$ effect-site target propofol concentration. The ventilator setting was adjusted to an end-tidal carbon dioxide tension $\left(\mathrm{P}_{\mathrm{ET}} \mathrm{CO}_{2}\right)$ of $35-40 \mathrm{mmHg}$ during the study. The doses of anesthetics were adjusted to maintain BIS values between 40 and 60 during surgery. All patients received a continuous infusion of acetate Ringer's solution at a rate of $5 \mathrm{~mL} / \mathrm{kg} / \mathrm{h}$ during the surgery. No additional rocuronium was given during the maintenance of anesthesia.

At the end of surgery, $20 \mathrm{mg} / \mathrm{kg}$ body weight of acetaminophen was infused for $15 \mathrm{~min}$ for analgesia. Further, remifentanil was discontinued, and the 12-lead ECG measurements were performed under propofol anesthesia; $6 \mathrm{~min}$ after the end of the operation, a mixture of neostigmine and atropine or sugammadex was administered to reverse the neuromuscular blockade. The RR interval, QT interval, QTc interval, QTD, and QTcD were recorded at every minute from the end of surgery to $10 \mathrm{~min}$ after neuromuscular blockade reversal. Neuromuscular monitoring was not conducted during the recording.

From the ECG signals, consecutive beat-tobeat data were digitally recorded at a sampling rate of $2 \mathrm{~ms}$. The QT intervals were evaluated using QTD-1 ${ }^{\mathrm{TM}}$ (Fukuda Denshi Co. Ltd., Tokyo, Japan), which detected the onset of the $\mathrm{Q}$ wave and the end of the T wave. This software sets the onset of the $\mathrm{Q}$ wave as the intersection of a threshold level with the differential of the $\mathrm{Q}$ wave, and the end of the $\mathrm{T}$ wave as the intersection of a threshold level with the differential of the T wave. The software used for the differential threshold technique has previously been described in detail $[18,19]$. The QT intervals were measured for all 12 ECG leads, and corrected using Bazett's and Fredericia's formulae. The QTD was defined as the difference between the maximum and minimum average QT intervals in the 12-lead ECG. Similarly, the QTcD was defined as the difference between the maximum and minimum average QTc intervals. The average value of data derived from three successive beats for each lead was used for analysis. Leads in which the end of the $T$ wave could not be clearly detected were excluded from this study. The RR interval, mean arterial pressure (MAP), BIS, QT, QTc, QTD, and QTcD were analyzed. To assess the changes in the QT, QTc, QTD, and QTcD with respect to baseline, the ratio of the measured value to the baseline (pre-dose value) was calculated.

\section{Statistical Analyses}

Statistical analysis was performed using Prism 6 (GraphPad, La Jolla, CA, USA). Data are expressed as mean \pm standard deviation. Patient characteristics were analyzed using Student's $t$ test and Fisher's exact test. The changes in RR interval, QT, QTc, QTD, QTcD, and BIS value were analyzed using two-way analysis of variance. When a significant overall effect was detected, Bonferroni's post hoc test was conducted. In all analyses, the probability of detecting a significant difference was set at the $5 \%$ level $(p<0.05)$. A sample size of 17 subjects in each group was considered adequate, based 
Table 1 Patient characteristics

\begin{tabular}{llll}
\hline & $\begin{array}{l}\text { Group S } \\
(\boldsymbol{n}=\mathbf{2 0})\end{array}$ & $\begin{array}{l}\text { Group N } \\
(\boldsymbol{n}=\mathbf{2 0})\end{array}$ & $\boldsymbol{p}$ value \\
\hline ASA-PS I/II & $14 / 6$ & $15 / 5$ & 1.00 \\
$\begin{array}{l}\text { Sex (male/ } \\
\text { female) }\end{array}$ & $12 / 8$ & $14 / 6$ & 0.74 \\
Age (years) & $41.5 \pm 13.8$ & $44 \pm 12.5$ & 0.60 \\
Height $(\mathrm{cm})$ & $163.8 \pm 8.7$ & $166 \pm 10.5$ & 0.48 \\
Weight $(\mathrm{kg})$ & $63.4 \pm 15.8$ & $63.4 \pm 16$ & 0.99 \\
BMI $\left(\mathrm{kg} / \mathrm{m}^{2}\right)$ & $23.4 \pm 3.9$ & $23 \pm 3.2$ & 0.61 \\
\hline
\end{tabular}

Data are presented as mean \pm standard deviation ASA-PS American Society of Anesthesiologists Classification of Physical Status, BMI body mass index

on a previous study [16], to detect a difference of $20 \mathrm{~ms}$ in the QTcD between the two groups at a power of $80 \%$, with $\alpha=0.05$.

\section{RESULTS}

Table 1 shows the patient characteristics for the present study. Forty patients were enrolled in this study. There were no significant differences in age, sex, ASA physical status, height, body weight, or body mass index (BMI) between the two groups. No complications were observed in this study. There was no patient with an abnormal RR interval, QT interval, QTc interval, QT dispersion, or QTc dispersion in either group. No arrythmia was observed before and after reversal of neuromuscular blockade.

Table 2 shows the measured values of RR interval, mean arterial pressure (MAP) and BIS. The RR interval in group $\mathrm{N}$ was significantly shorter than that in group S 1 min after reversal of neuromuscular blockade $(p<0.05)$. Furthermore, the RR interval was shorter than the baseline value in group $\mathrm{N}(p<0.05)$. In contrast, there were no significant differences in the MAP or BIS between the $\mathrm{N}$ and $\mathrm{S}$ groups.

Table 3 shows the absolute values of QT, QT corrected using Bazett' formula (QTcB), QT corrected using Fredericia's formula (QTcF), QTD, QTcB dispersion (QTcBD), and QTcF dispersion (QTcFD). There were no significant differences in the absolute values of QT, QTcB, QTcF, QTD, QTcBD, and QTcFD between groups $\mathrm{N}$ and $\mathrm{S}$ before the operation (QT: $\mathrm{N}$ $377 \pm 26 \mathrm{~ms}, \quad \mathrm{~S} \quad 365 \pm 25 \mathrm{~ms} ; \quad$ QTcB: $\mathrm{N}$ $410 \pm 26$ ms, S $420 \pm 24$ ms; QTcF: N $409 \pm 22$, S $\quad 405 \pm 21$; QTD: $\mathrm{N} 36.2 \pm 19.4 \mathrm{~ms}, \quad \mathrm{~S}$ $32 \pm 17 \mathrm{~ms}$; QTcBD: N $37 \pm 15 \mathrm{~ms}$, S

Table 2 Measured values of variables

\begin{tabular}{lllllllll}
\hline Group & Baseline & T0 & T1 & T2 & T3 & T5 & T7 & T10 \\
\hline RR (ms) & & & & & & & & \\
Sugammadex & $889 \pm 106$ & $889 \pm 107$ & $896 \pm 115$ & $883 \pm 129$ & $872 \pm 137$ & $875 \pm 128$ & $869 \pm 131$ & $849 \pm 151$ \\
Neostigmine & $884 \pm 122$ & $870 \pm 121$ & $763 \pm 125^{*}$ & $795 \pm 116$ & $841 \pm 118$ & $907 \pm 121$ & $907 \pm 138$ & $915 \pm 150$ \\
MAP (mmHg) & & & & & & & & \\
Sugammadex & $71 \pm 11$ & $72 \pm 11$ & $72 \pm 10$ & $70 \pm 9$ & $73 \pm 10$ & $75 \pm 11$ & $74 \pm 10$ & $76 \pm 12$ \\
Neostigmine & $71 \pm 11$ & $72 \pm 11$ & $73 \pm 11$ & $72 \pm 10$ & $74 \pm 11$ & $76 \pm 11$ & $76 \pm 10$ & $79 \pm 12$ \\
BIS & & & & & & & & \\
Sugammadex & $42 \pm 7$ & $41 \pm 8$ & $40 \pm 8$ & $41 \pm 9$ & $42 \pm 10$ & $41 \pm 8$ & $42 \pm 7$ & $43 \pm 10$ \\
Neostigmine & $41 \pm 13$ & $41 \pm 15$ & $39 \pm 12$ & $42 \pm 13$ & $42 \pm 10$ & $42 \pm 13$ & $43 \pm 16$ & $44 \pm 9$ \\
\hline
\end{tabular}

Data are presented as mean \pm standard deviation

$T 0$ reversal of neuromuscular blockade, T1-T10 1-10 min after reversal, RR RR interval, MAP mean arterial pressure, BIS bispectral index

${ }^{*} p<0.05$ versus sugammadex group 
Table 3 Measurement values of variables

\begin{tabular}{lcccccccc}
\hline Group & Baseline & T0 & T1 & T2 & T3 & T5 & T7 & T10 \\
\hline QT (ms) & & & & & & & & \\
Sugammadex & $389 \pm 30$ & $390 \pm 27$ & $389 \pm 29$ & $388 \pm 27$ & $387 \pm 28$ & $386 \pm 27$ & $385 \pm 28$ & $380 \pm 28$ \\
Neostigmine & $392 \pm 26$ & $390 \pm 23$ & $374 \pm 25$ & $375 \pm 24$ & $379 \pm 24$ & $390 \pm 25$ & $397 \pm 27$ & $398 \pm 27$ \\
QTcB (ms) & & & & & & & & \\
Sugammadex & $413 \pm 24$ & $414 \pm 24$ & $413 \pm 23$ & $414 \pm 27$ & $415 \pm 27$ & $413 \pm 23$ & $412 \pm 24$ & $415 \pm 23$ \\
Neostigmine & $412 \pm 20$ & $414 \pm 22$ & $424 \pm 19$ & $414 \pm 20$ & $410 \pm 23$ & $406 \pm 20$ & $407 \pm 25$ & $409 \pm 23$ \\
QTcF (ms) & & & & & & & & \\
Sugammadex & $404 \pm 21$ & $404 \pm 20$ & $403 \pm 21$ & $404 \pm 22$ & $404 \pm 21$ & $402 \pm 19$ & $401 \pm 20$ & $400 \pm 19$ \\
Neostigmine & $406 \pm 18$ & $406 \pm 18$ & $407 \pm 16$ & $402 \pm 20$ & $399 \pm 19$ & $399 \pm 18$ & $405 \pm 20$ & $404 \pm 16$ \\
QTD (ms) & & & & & & & & \\
Sugammadex & $36 \pm 15$ & $38 \pm 16$ & $36 \pm 17$ & $35 \pm 20$ & $33 \pm 15$ & $35 \pm 15$ & $36 \pm 19$ & $37 \pm 20$ \\
Neostigmine & $38 \pm 21$ & $40 \pm 24$ & $38 \pm 20$ & $39 \pm 22$ & $42 \pm 24$ & $41 \pm 23$ & $43 \pm 24$ & $41 \pm 25$ \\
QTcBD (ms) & & & & & & & & \\
Sugammadex & $38 \pm 15$ & $40 \pm 17$ & $38 \pm 18$ & $40 \pm 22$ & $37 \pm 15$ & $40 \pm 18$ & $38 \pm 19$ & $38 \pm 15$ \\
Neostigmine & $38 \pm 24$ & $42 \pm 27$ & $44 \pm 24$ & $44 \pm 25$ & $52 \pm 33$ & $39 \pm 25$ & $41 \pm 25$ & $39 \pm 20$ \\
QTcFD (ms) & & & & & & & & \\
Sugammadex & $39 \pm 16$ & $39 \pm 17$ & $38 \pm 18$ & $39 \pm 21$ & $38 \pm 19$ & $39 \pm 19$ & $41 \pm 18$ & $42 \pm 19$ \\
Neostigmine & $38 \pm 23$ & $39 \pm 24$ & $42 \pm 21$ & $44 \pm 25$ & $49 \pm 30$ & $39 \pm 25$ & $43 \pm 27$ & $40 \pm 23$ \\
\hline Data & & & & & & &
\end{tabular}

Data are presented as mean \pm standard deviation

T0 reversal of neuromuscular blockade, T1-T10 1-10 min after reversal, $R R$ RR interval, $Q T$ QT interval, QTcB QT corrected using Bazzett's formula, QTcF QT corrected using Fredericia's formula, QTD QT dispersion, QTcBD QT dispersion corrected using Bazzett's formula, QTcFD QT dispersion corrected using Fredericia's formula

$35 \pm 19 \mathrm{~ms} ;$ and QTcFD: N $38 \pm 20 \mathrm{~ms}, \quad \mathrm{~S}$ $35 \pm 15 \mathrm{~ms})$. The measured QT, QTcB, and QTcF values at baseline were within the normal range. There were no significant differences between the sexes in QT and QTcB at baseline (male: QT, N $388 \pm 27 \mathrm{~ms}$, S $384 \pm 26 \mathrm{~ms}$; QTcB, N $410 \pm 28 \mathrm{~ms}, \quad \mathrm{~S} \quad 411 \pm 21 \mathrm{~ms} ;$ and female: QT, N $407 \pm 24 \mathrm{~ms}, \quad$ S $401 \pm 21 \mathrm{~ms}$; QTcB, N $423 \pm 14$ ms, S $419 \pm 33$ ms). During the measurement, there were no significant differences in the absolute QT, QTcB, QTcF, QTD, QTcBD, and QTcFD values between groups $\mathrm{N}$ and $\mathrm{S}$.

Table 4 shows the ratios of the measured values to the baseline values of QT, QTcB, QTcF,
QTD, QTcBD, and QTcFD. The ratio of the QT interval to the baseline in group $\mathrm{N}$ was slightly, but significantly, decreased during the 1-3-min interval after reversal of neuromuscular blockade compared with group S $(p<0.05)$. Similarly, the ratio of the QT interval was decreased during the 1-3 min interval in group $\mathrm{N}$ compared to baseline $(p<0.05)$. In contrast, the ratio of the QTcB, but not the QTcF, 1 min after reversal of neuromuscular blockade to the baseline in group $\mathrm{N}$ was significantly increased compared with group $S(p<0.05)$. Furthermore, the ratio of the QTcB interval in group $\mathrm{N}$ was slightly increased $1 \mathrm{~min}$ after reversal from the baseline value $(p<0.05)$. 
Table 4 Ratios of measured values of variables

\begin{tabular}{|c|c|c|c|c|c|c|c|}
\hline Group & $T 0$ & $T 1$ & $T 2$ & $T 3$ & $T 5$ & $T 7$ & $T 10$ \\
\hline \multicolumn{8}{|l|}{ QT/baseline } \\
\hline Sugammadex & $1.00 \pm 0.02$ & $0.99 \pm 0.02$ & $0.99 \pm 0.03$ & $0.99 \pm 0.04$ & $0.98 \pm 0.04$ & $0.98 \pm 0.03$ & $0.98 \pm 0.05$ \\
\hline Neostigmine & $1.00 \pm 0.01$ & $0.95 \pm 0.03^{*, \dagger}$ & $0.96 \pm 0.04^{*, \dagger}$ & $0.97 \pm 0.03^{* \dagger}$ & $0.99 \pm 0.03$ & $1.01 \pm 0.03$ & $1.00 \pm 0.05$ \\
\hline \multicolumn{8}{|l|}{ QTcB/baseline } \\
\hline Sugammadex & $1.00 \pm 0.01$ & $0.99 \pm 0.02$ & $1.00 \pm 0.02$ & $1.00 \pm 0.02$ & $1.00 \pm 0.01$ & $1.00 \pm 0.02$ & $1.00 \pm 0.02$ \\
\hline Neostigmine & $1.00 \pm 0.02$ & $1.03 \pm 0.04^{*, \dagger}$ & $1.00 \pm 0.02$ & $0.99 \pm 0.02$ & $0.98 \pm 0.02$ & $0.99 \pm 0.04$ & $0.98 \pm 0.03$ \\
\hline \multicolumn{8}{|l|}{ QTcF/baseline } \\
\hline Sugammadex & $1.00 \pm 0.02$ & $1.00 \pm 0.02$ & $1.00 \pm 0.01$ & $1.00 \pm 0.01$ & $0.99 \pm 0.02$ & $1.00 \pm 0.02$ & $0.99 \pm 0.02$ \\
\hline Neostigmine & $1.00 \pm 0.02$ & $1.00 \pm 0.02$ & $0.98 \pm 0.02$ & $0.99 \pm 0.05$ & $0.99 \pm 0.02$ & $0.99 \pm 0.03$ & $0.99 \pm 0.02$ \\
\hline \multicolumn{8}{|l|}{ QTD/baseline } \\
\hline Sugammadex & $1.04 \pm 0.29$ & $1.04 \pm 0.21$ & $1.04 \pm 0.34$ & $1.06 \pm 0.38$ & $1.16 \pm 0.45$ & $1.05 \pm 0.34$ & $1.03 \pm 0.29$ \\
\hline Neostigmine & $1.04 \pm 0.23$ & $1.11 \pm 0.42$ & $1.10 \pm 0.30$ & $1.15 \pm 0.49$ & $1.09 \pm 0.58$ & $1.18 \pm 0.49$ & $1.19 \pm 0.42$ \\
\hline \multicolumn{8}{|c|}{ QTcBD/baseline } \\
\hline Sugammadex & $1.08 \pm 0.47$ & $0.97 \pm 0.13$ & $0.93 \pm 0.31$ & $0.94 \pm 0.25$ & $1.01 \pm 0.20$ & $0.97 \pm 0.28$ & $0.93 \pm 0.20$ \\
\hline Neostigmine & $1.13 \pm 0.2$ & $1.31 \pm 0.39^{*, \dagger}$ & $1.32 \pm 0.33^{*, \dagger}$ & $1.37 \pm 0.45^{*, \dagger}$ & $1.21 \pm 0.40$ & $1.23 \pm 0.45$ & $1.07 \pm 0.28$ \\
\hline \multicolumn{8}{|c|}{ QTcFD/baseline } \\
\hline Sugammadex & $0.99 \pm 0.28$ & $1.00 \pm 0.37$ & $1.04 \pm 0.30$ & $1.03 \pm 0.36$ & $1.02 \pm 0.36$ & $1.10 \pm 0.34$ & $1.07 \pm 0.31$ \\
\hline Neostigmine & $1.07 \pm 0.23$ & $1.22 \pm 0.35$ & $1.22 \pm 0.27$ & $1.38 \pm 0.48^{*, \dagger}$ & $1.15 \pm 0.32$ & $1.19 \pm 0.40$ & $1.04 \pm 0.29$ \\
\hline
\end{tabular}

Data are presented as mean \pm standard deviation

T0 reversal of neuromuscular blockade, T1-T10 1-10 min after reversal, $R R$ RR interval, QT QT interval, QTcB QT corrected using Bazzett's formula, QTcF QT corrected using Fredericia's formula, QTD QT dispersion, QTcBD QT dispersion corrected using Bazzett's formula, $Q T c F D$ QT dispersion corrected using Fredericia's formula ${ }^{*} p<0.05$ versus sugammadex group. ${ }^{\dagger} p<0.05$ versus baseline ratio

There was no significant difference in the ratio of the QTD to baseline between the $\mathrm{N}$ and $S$ groups. In contrast, neostigmine significantly increased the ratio of the QTcBD to baseline in group $\mathrm{N}$ during the 1-3 min interval after reversal of neuromuscular blockade compared with group $\mathrm{S}(p<0.05)$. Moreover, the ratio of the QTcBD in group $\mathrm{N}$ was significantly increased from baseline 1-3 min after reversal of neuromuscular blockade $(p<0.05)$. Similarly, the ratio of QTcFD in group $\mathrm{N}$ was significantly increased $3 \mathrm{~min}$ after reversal of neuromuscular blockade compared with group $S$ and baseline $(p<0.05)$.

\section{DISCUSSION}

In this study, we evaluated the impact of the neuromuscular blockade reversal agents, sugammadex and neostigmine on QTD, a predictor of ventricular arrhythmias, under propofol anesthesia, which has not been reported previously.

\section{Effects of Reversal of Neuromuscular Blockade on QT and QTC}

Sugammadex, a selective relaxant-binding agent, is recommended for reversal of moderate 
or deep muscle relaxation induced by non-depolarizing neuromuscular blockade. It has been reported in several studies that supra-therapeutic or therapeutic intravenous doses of sugammadex did not prolong QTc during general anesthesia [20]; however, Vanacker et al. reported that sugammadex, but not propofol, administered at less than 1.5 minimum alveolar concentration sevoflurane, prolonged the QTC interval [21]. This discrepancy was likely due to the prolongation of the QT interval by sevoflurane, as inhaled anesthetics at therapeutic concentrations prolong the QT interval [22]. Hence, the present study was conducted under propofol anesthesia to exclude the effects of volatile anesthetic agents on the QT interval. The results of this study show that sugammadex at therapeutic doses ( $4 \mathrm{mg} / \mathrm{kg}$ body weight) is not likely to prolong QT or QTc, at least under propofol anesthesia.

Prolongation of QT is induced by an imbalance in the cardiac sympathetic tone [23]. Such an imbalance is observed when using an anticholinesterase-anticholinergic combination [2]. Neostigmine itself may cause adverse cardiovascular effects, such as bradyarrhythmia. To prevent such anticholinesterase-induced effects, atropine is commonly added for reversal of neuromuscular blockade. Therefore, reversal of neuromuscular blockade by neostigmine and atropine may result in a prolonged QT interval by affecting the sympathetic tone [23]. While a previous study reported that the combination of neostigmine $(0.03 \mathrm{mg} / \mathrm{kg}$ body weight $)$ and atropine did not prolong the QTc interval under sevoflurane and $\mathrm{N}_{2} \mathrm{O}$ anesthesia [10], de Kam et al. reported that administration of neostigmine and glycopyrrolate prolonged the QT interval under propofol anesthesia [12]. Therefore, the authors proposed that anticholinergic agents should be avoided in patients with cardiovascular disease [12]. Our results are consistent with those of de Kam et al. in terms of QTcB.

Although QTc, corrected by the RR interval, was prolonged by a mixture of neostigmine and atropine, the QT interval was shortened, rather than remaining unchanged, in our study. According to previous reports, the increase in heart rate induced by atropine shortens the uncorrected QT interval [24]. Therefore, the difference in the effect on QT vs. QTc could be attributed to the effects of atropine.

\section{Effects of Reversal of Neuromuscular Blockade on QTD and QTcD}

Increased QTD is observed in patients with myocardial infarction [15], subarachnoid hemorrhage [25], or diabetes mellitus [26]. De Bruyne et al. suggested that QTD is a reliable predictor of cardiac mortality in elderly men and women [14]. Day et al. revealed that QTcD was significantly increased in patients with arrhythmogenic QT prolongation (Romano Ward syndrome, Jervell and Lange-Nielsen syndrome, etc.) compared with patients with QT prolongation induced by sotalol [13]. Furthermore, QT dispersion, QTc dispersion, and QT dispersion ratio (divided by cycle length and expressed as a percentage) in patients with acute myocardial infarction exhibiting ventricular fibrillation were significantly higher than those in patients with unstable angina [27]. These results emphasize that prolongation of QTcD is associated with arrhythmogenicity. Several studies have been conducted to evaluate the impact of noxious stimuli on hemodynamic status during general anesthesia, based on QTD. We previously reported that neither sugammadex nor neostigmine had any effects on QTD and QTcD under sevoflurane anesthesia [16]. The effect of general anesthetics on QTD remains unclear. While some studies have reported that sevoflurane does not prolong QTD $[28,29]$, others have shown that sevoflurane or other volatile anesthetics significantly prolong QTD compared with baseline values [1]. Propofol has been reported to have no effect on QTD. We, therefore, used propofol anesthesia to avoid the effects of sevoflurane on QTD. We hypothesized that the combination of neostigmine and atropine may alter the QTcD under propofol anesthesia. The relative QTcD from baseline was significantly increased 1-3 min after administration of neostigmine and atropine compared with that after administration of sugammadex. These results imply that neostigmine prolongs the $\mathrm{QTCD}$, which may increase 
the risk of ventricular arrhythmia, whereas sugammadex has no effect on QTcD under propofol anesthesia. In contrast, sugammadex had no effect on QTD and QTcD under propofol anesthesia compared with the mixture of neostigmine and atropine. Thus, sugammadex has fewer adverse effects in terms of cardiac complications than neostigmine.

Although the safety and usefulness of sugammadex have been clinically established, there are some indications for the use of neostigmine as a reversal agent. In some cases, sugammadex induces anaphylaxis, which may cause deterioration of the patient's general condition [30]. In patients with a medical history of sugammadex-induced allergy, neostigmine must be used to avoid serious allergic reactions. Neostigmine is one of the agents that can be used for reversing residual neuromuscular blockade in patients with suspected sugammadex-induced hypersensitivity.

\section{Study Limitations}

The present study was limited with regard to evaluation of the exact cardiovascular risk of neuromuscular blockade reversal. Our results were obtained under propofol anesthesia (the BIS value was maintained between 40 and 60). In clinical situations, neuromuscular blockade is reversed under many different conditions, such as light sevoflurane anesthesia, propofol anesthesia, or conscious states. Therefore, assessment of the effects of sugammadex and neostigmine on QTD under other conditions is essential to clarify the effects of these agents on QTD.

In the present study, QT correction was conducted using Bazzett's and Fredericia's formulae. In case of Bazzett's formula, we found a significant increase in QTcD (QTcBD) ratio 1-3 min after reversal of neuromuscular blockade. On the contrary, a significant decrease was not detected in QTcFD after 1-2 min, using Fredericia's formula. Similarly, unlike QTcB, QTcF ratio remained unchanged $1 \mathrm{~min}$ after reversal. It has been proposed that QT at heart rate below 60 and over $90 \mathrm{bpm}$ should not corrected using Bazzett's formula [31].
Therefore, the use of Bazzett' formula for general anesthesia is likely to result in overcorrection of QT and QTD, especially after administration of atropine.

\section{CONCLUSIONS}

Our results show that sugammadex at therapeutic doses has no effect on the RR interval, QT, QTc, QTD, or QTcD, whereas a mixture of neostigmine and atropine increases the QTc and QTcD. Although serious hemodynamic changes rarely occur when using neostigmine for neuromuscular blockade reversal in clinical practice, neostigmine is likely to increase the risk of ventricular arrhythmia, and should, therefore, be avoided for patients with cardiac complications. Furthermore, we emphasize that sugammadex might be a safer option as a neuromuscular blockade reversal agent for patients with cardiac complications.

\section{ACKNOWLEDGEMENTS}

We thank the participants of the study.

Funding. No funding or sponsorship was received for this study or publication of this article. The article processing charges were funded by the authors.

Authorship. All named authors meet the International Committee of Medical Journal Editors (ICMJE) criteria for authorship for this article, take responsibility for the integrity of the work as a whole, and have given their approval for this version to be published.

Writing Assistance. Writing assistance in the preparation of this article was provided by Editage. Financial support for this assistance was provided by Shigeki Yamaguchi.

Disclosures. Yusuke Yamashita, Yoshiyuki Kimura, Toshifumi Takasusuki, Makoto Komatsuzaki, and Shigeki Yamaguchi have nothing to disclose. 
Compliance with Ethics Guidelines. All procedures performed in studies involving human participants were in accordance with the ethical standards of the institutional and national research committee and the 1964 Helsinki declaration and its later amendments or comparable ethical standards. Informed consent was obtained from all individual participants included in the study.

Data Availability. The datasets generated during and/or analyzed during the current study are available from the corresponding author on reasonable request.

Open Access. This article is distributed under the terms of the Creative Commons Attribution-NonCommercial 4.0 International License (http://creativecommons.org/licenses/ by-nc/4.0/), which permits any noncommercial use, distribution, and reproduction in any medium, provided you give appropriate credit to the original author(s) and the source, provide a link to the Creative Commons license, and indicate if changes were made.

\section{REFERENCES}

1. Güler N, Bilge M, Eryonucu B, Kati I, Demirel CB. The effects of halothane and sevoflurane on QT dispersion. Acta Cardiol. 1999;54:311-5.

2. Saarnivaara L, Simola M. Effects of four anticholinesterase-anticholinergic combinations and tracheal extubation on QTc interval of the ECG, heart rate and arterial pressure. Acta Anaesthesiol Scand. 1998;42:460-3.

3. Bevan DR, Donati F, Kopman AF. Reversal of neuromuscular blockade. Anesthesiology. 1992;77:785-805.

4. Backman SB, Bachoo M, Polosa C. Mechanism of the bradycardia produced in the cat by the anticholinesterase neostigmine. J Pharmacol Exp Ther. 1993;265:194-200.

5. Sawasdiwipachai P, Laussen PC, McGowan FX, Smoot L, Casta A. Cardiac arrest after neuromuscular blockade reversal in a heart transplant infant. Anesthesiology. 2007;107:663-5.
6. Bertolizio G, Yuki K, Odegard K, Collard V, Dinardo J. Cardiac arrest and neuromuscular blockade reversal agents in the transplanted heart. J Cardiothorac Vasc Anesth. 2013;27:1374-8.

7. Srivastava A, Hunter JM. Reversal of neuromuscular block. Br J Anaesth. 2009;103:115-29.

8. Pleym H, Bathen J, Spigset O, Gisvold SE. Ventricular fibrillation related to reversal of the neuromuscular blockade in a patient with long QT syndrome. Acta Anaesthesiol Scand. 1999;43:352-5.

9. Shields JA. Heart block and prolonged Q-Tc interval following muscle relaxant reversal: a case report. AANA J. 2008;76:41-5.

10. Kizilay D, Dal D, Saracoglu KT, Eti Z, Gogus FY. Comparison of neostigmine and sugammadex for hemodynamic parameters in cardiac patients undergoing noncardiac surgery. J Clin Anesth. 2016;28:30-5.

11. Nicholson WT, Sprung J, Jankowski CJ. Sugammadex: a novel agent for the reversal of neuromuscular blockade. Pharmacotherapy. 2007;27:1181-8.

12. de Kam PJ, Grobara P, Dennie J, et al. Effect of sugammadex on QT/QTc interval prolongation when combined with QTc-prolonging sevoflurane or propofol anaesthesia. Clin Drug Investig. 2013;33:545-51.

13. Day CP, McComb JM, Campbell RW. QT dispersion: an indication of arrhythmia risk in patients with long QT intervals. Br Heart J. 1990;63:342-4.

14. de Bruyne MC, Hoes AW, Kors JA, Hofman A, van Bemmel JH, Grobbee DE. QTc dispersion predicts cardiac mortality in the elderly: the Rotterdam Study. Circulation. 1998;97:467-72.

15. Okin PM, Devereux RB, Howard BV, Fabsitz RR, Lee ET, Welty TK. Assessment of QT interval and QT dispersion for prediction of all-cause and cardiovascular mortality in American Indians: the Strong Heart Study. Circulation. 2000;101:61-6.

16. Nagashima S, Takasusuki T, Yamaguchi S, Hamaguchi $\mathrm{S}$. Effects of neostigmine and sugammadex on QT interval and QT dispersion. Dokkyo J Med Sci. 2016;43:15-22.

17. Loeckinger A, Kleinsasser A, Maier S, et al. Sustained prolongation of the QTc interval after anesthesia with sevoflurane in infants during the first 6 months of life. Anesthesiology. 2003;98:639-42.

18. McLaughlin NB, Campbell RW, Murray A. Accuracy of four automatic QT measurement techniques in 
cardiac patients and healthy subjects. Heart. 1996;76:422-6.

19. Xue Q, Reddy S. Algorithms for computerized QT analysis. J Electrocardiol. 1998;30:181-6.

20. de Kam PJ, van Kuijk J, Smeets J, Thomsen T, Peeters P. Sugammadex is not associated with QT/QTc prolongation: methodology aspects of an intravenous moxifloxacin-controlled thorough QT study. Int J Clin Pharmacol Ther. 2012;50:595-604.

21. Vanacker BF, Vermeyen KM, Struys MM, et al. Reversal of rocuronium-induced neuromuscular block with the novel drug sugammadex is equally effective under maintenance anesthesia with propofol or sevoflurane. Anesth Analg. 2007;104:563-8.

22. Kleinsasser A, Kuenszberg E, Loeckinger A, et al. Sevoflurane, but not propofol, significantly prolongs the Q-T interval. Anesth Analg. 2000;90:25-7.

23. Schwartz PJ, Stone HL. Effects of unilateral stellectomy upon cardiac performance during exercise in dogs. Circ Res. 1979;44:637-45.

24. Kawataki M, Kashima T, Toda H, Tanaka H. Relation between QT interval and heart rate. Applications and limitations of Bazett's formula. J Electrocardiol. 1984;17:371-5.
25. Sato K, Kato M, Yoshimoto T. QT intervals and QT dispersion in patients with subarachnoid hemorrhage. J Anesth. 2001;15:74-7.

26. Aytemir K, Aksöyek S, Ozer N, Gürlek A, Oto A. QT dispersion and autonomic nervous system function in patients with type 1 diabetes. Int $\mathrm{J}$ Cardiol. 1998;65:45-50.

27. Higham PD, Furniss SS, Campbell RW. QT dispersion and components of the QT interval in ischaemia and infarction. Br Heart J. 1995;73:32-6.

28. Gürkan Y, Canatay H, Agacdiken A, Ural E, Toker K. Effects of halothane and sevoflurane on QT dispersion in paediatric patients. Paediatr Anaesth. 2003;13:223-7.

29. Ugur B, Sen S, Tekten T, et al. Effects of sevoflurane on QT dispersion and heart rate variability. Adv Ther. 2006;23:439-45.

30. Miyazaki Y, Sunaga H, Kida K, et al. Incidence of anaphylaxis associated with sugammadex. Anesth Analg. 2018;26:1505-8.

31. Luo S, Michler K, Johnston P, Macfarlane PW. A comparison of commonly used QT correction formulae: the effect of heart rate on the QTc of normal ECGs. J Electrocardiol. 2004;37(Suppl):81-90. 